\title{
Recurrence and Disease-Free Survival in Head and Neck Squamous Cell Carcinoma After Margin-Free Resection on Frozen Section: An Institutional Perspective
}

Atif A. Hashmi ${ }^{1}$, Syeda N. Iftikhar ${ }^{1}$, Rimsha Haider ${ }^{2,}{ }^{3}$, Nabeel N. Baig ${ }^{4}$, Muhammad Ghani Asif ${ }^{5}$, Muhammad Irfan 6

1. Pathology, Liaquat National Hospital and Medical College, Karachi, PAK 2. Internal Medicine, Liaquat National Hospital and Medical College, Karachi, PAK 3. Emergency Medicine, National Institute of Blood Diseases and Bone Marrow Transplantation, Karachi, PAK 4. Research and Development, College of Physicians and Surgeons, Karachi, PAK 5. Pathology, Multan Medical and Dental College, Multan, PAK 6. Statistics, Liaquat National Hospital and Medical College, Karachi, PAK

Corresponding author: Atif A. Hashmi, atifhashmi345@gmail.com

\section{Abstract}

\section{Introduction}

The most important factor determining survival in patients with head and neck squamous cell carcinoma (HNSCC) is a disease recurrence. A high rate of recurrence was noted in previous studies conducted in Pakistan; however, these studies did not consider margin status as inadequate margin clearance leads to disease recurrence. In this study, we determined cancer recurrence in patients with HNSCC after nullifying this factor.

\section{Methods}

This cross-sectional observational study was conducted in Liaquat National Hospital (LNH) for a duration of three years. Data collection period was from January 2015 to December 2017. A total of 150 patients that underwent surgery at LNH for HNSCC with margin-free frozen sections were included in the study. Pathological tumor characteristics such as tumor type, size, depth of invasion and nodal status were determined.

\section{Results}

The mean age of the patients was $50.31 \pm 12.90$ with mean tumor size of $3.38 \pm 1.76$. Nodal metastases were present in $45.3 \%$ cases with $17.3 \%$ showing extranodal extension. Recurrence was observed in $66 \%$ of cases with median disease-free survival of 12 months and perineural invasion was noted in $12 \%$ cases. We found a significant association of disease recurrence with larger tumor size, depth of invasion and extranodal extension. Moreover, younger age ( $<30$ years) and older age ( $>50$ years) groups showed higher rates of recurrence than the middle age group (30-50 years). Similarly, univariate and multivariate analyses revealed that tumors with $\geqslant 1 \mathrm{~cm}$ depth of invasion and the presence of extranodal extension were more likely to have disease recurrence than tumors with $<1 \mathrm{~cm}$ depth of invasion and without extranodal extension. Survival analysis using the Kaplan-Meier method for HNSCC revealed a significant difference in disease-free survival in patients with more than $2 \mathrm{~cm}$ tumor size and $\geqslant 1 \mathrm{~cm}$ depth of invasion than cases with $\leqslant 2 \mathrm{~cm}$ tumor size and $<1 \mathrm{~cm}$ depth of invasion.

Hashmi et al. This is an open access article distributed under the terms of the Creative Commons Attribution License CC-BY 4.0., which permits unrestricted use, distribution, and reproduction in any medium, provided the original author and source are credited.

\section{Conclusion}

A high rate of disease recurrence for HNSSC was noted in our study, despite margin-free primary tumor resection. Apart from tumor size and depth of invasion, extranodal extension was significantly associated with disease recurrence in HNSCC. This signifies a need for margin evaluation of neck dissection specimen in cases with extranodal extension.

Categories: Otolaryngology, Pathology, Oncology

Keywords: head and neck squamous cell carcinoma (hnscc), oral squamous cell carcinoma, frozen section, recurrence, disease-free survival, margin-free resection, gutka, areca nut, human papilloma virus (hpv)

\section{Introduction}

Our region (South-east Asia) is considered a high-risk area for head and neck squamous cell carcinoma (HNSCC) owing to the wide use of areca-nut chewing in the form of gutka and pan [1-3]. It was proposed that areca-nut induced HNCC is more prevalent than human papilloma virus (HPV)-induced HNSCC in this region [4]. These cancers are considered more aggressive than HPV-induced oral cancers in western countries. 

$[5,6]$.

The most important factor determining survival in patients with HNSCC is disease recurrence. A high rate of recurrence was noted in previous studies conducted in Pakistan [7]. Whether this high rate of recurrence is secondary to inadequate margin clearance or not is unknown as margin-free resection is the most important factor determining recurrence in most cancers. Most of the previous studies that evaluated recurrence in HNSCC in our population did not consider margin status as inadequate margin clearance leads to disease recurrence, and thus is an important confounding factor. In this study, we determined cancer recurrence in patients with HNSCC after nullifying this factor.

\section{Materials And Methods}

This cross-sectional observational study was conducted in Liaquat National Hospital (LNH) for a duration of three years. Data collection period was from January 2015 to December 2017. Patients that underwent surgery at LNH for HNSCC with margin-free frozen sections were included in the study. More than $1 \mathrm{~mm}$ tumor-free margin on the frozen section was taken as tumor-free resection margin (Figure 1).
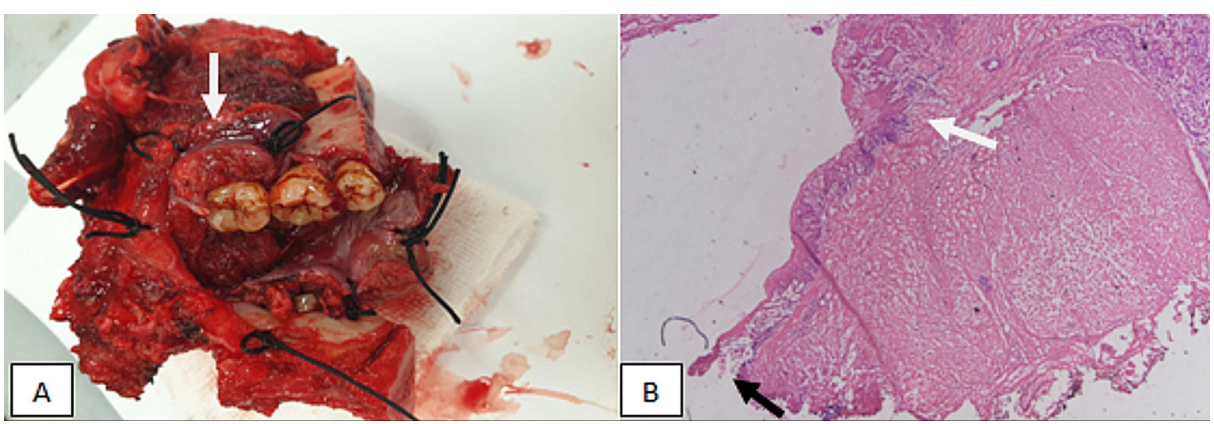

FIGURE 1: (A) Gross specimen of oral cancer specimen sent for frozen section, tumor present on buccal mucosa (white arrow), and margins are marked with sutures. (B) Microscopic frozen sections showing tumor (white arrow) more than $1 \mathrm{~mm}$ from the resection margin (black arrow).

All the cases included in the study had the diagnosis of squamous cell carcinoma on incisional biopsy before definitive surgical resection. All these patients presented in the Otorhinology clinics of LNH with head and neck mass or ulcerated lesions. After clinical examination and further workup, including computed tomography (CT) scans, incisional biopsy of the lesion was taken. Cases with post-neoadjuvant chemotherapy or radiation were excluded from the study along with patients having any evidence of systemic metastasis. Any patient with the positive margin on frozen section was also excluded from the study. Tumor present on resected margin or less than $1 \mathrm{~mm}$ distance of the tumor from the resected margin was considered a positive margin on the frozen section. Any case with positive margin on the final (paraffin) section was also excluded from the study. After approval from the research and ethical committee of the hospital, pathological and oncological records were evaluated and data were entered. Frozen section reports were assessed along with final histopathology reports of all patients. Pathological tumor characteristics such as tumor type, size, depth of invasion and nodal status were noted. The disease-free survival was determined by reviewing the oncological records.

All specimens (whole resected specimen) were received fresh for frozen section examination. After evaluation of size and dimensions of the specimen, the tumor was located and size and extent of the tumor were assessed. Gross distances of the tumor from all the marked (by the surgeon) surgical resection margins were measured. All margins were inked with different colored inks. If the resected margin was more than 1 $\mathrm{cm}$ from the tumor, then shaved sections were taken. Alternatively, if the gross distance of the tumor from the resected margin was less than $1 \mathrm{~cm}$, multiple radial sections were taken from the margin to measure the distance of the tumor from the margin microscopically. After frozen section reporting, specimens were put into the formalin-filled containers and kept for $24 \mathrm{~h}$ for fixation. After $24 \mathrm{~h}$, specimens were examined again and additional sections were taken from the tumor to assess tumor differentiation, perineural invasion and depth of invasion. Moreover, sections that were submitted for frozen sections were again assessed microscopically after formalin fixation to note any discrepancy from frozen section reports.

Data analysis was performed using Statistical Package for Social Sciences (Version 26.0, IBM Inc., Armonk, NY). Chi-square and Fisher exact tests were used to check the association. The odds ratio was computed using univariate logistic regression. The multivariate binary logistic regression was applied for variables that 


\section{Cureus}

were significant on univariate logistic regression. Survival analysis was done by the Kaplan-Meier method. P-values $\leqslant 0.05$ were considered as significant.

\section{Results}

\section{Clinicopathologic features of population under study}

A total of 150 cases of HNSCC, were included in the study. The mean age of the patients was $50.31 \pm 12.90$ with mean tumor size of $3.38 \pm 1.76$. Most of the tumors were between 2 and $4 \mathrm{~cm}$ tumor sizes (49.3\%), and $42.7 \%$ cases had a depth of invasion $\geqslant 1 \mathrm{~cm}$. Majority of the patients were male $(75.3 \%)$ with the oral cavity being the most common site of the tumor (69.3\%). Nodal metastases were present in $45.3 \%$ cases with $17.3 \%$ showing extranodal extension. Most of the tumors were keratinizing (60\%) and $62.7 \%$ were grade II (moderately differentiated). Recurrence was observed in $66 \%$ of cases with median disease-free survival of 12 months and perineural invasion was noted in $12 \%$ cases (Table 1 ).

Clinicopathological characteristic

Age (years)

Mean \pm SD

Age groups

$\leq 30$ years

17(11.3)

$31-50$ years

$>50$ years

68(45.3)

65(43.3)

Tumor size (cm)

Mean \pm SD

$3.38 \pm 1.76$

Tumor size groups

$\leq 2 \mathrm{~cm}$

$2.1-4 \mathrm{~cm}$

$>4 \mathrm{~cm}$

Depth of invasion $(\mathrm{cm})$

Mean \pm SD

$1.08 \pm 0.68$

Depth of invasion groups

$<1 \mathrm{~cm}$

79(52.7)

$\geq 1 \mathrm{~cm}$

71(47.3)

Disease-free survival (months)

Mean \pm SD

$25.27 \pm 22.51$

Median

Gender

Male

Female

Site of tumo

Oral cavity

104(69.3)

Lip

Tongue

Soft palate

8(5.3)

Nodal metastasis

Present
68(45.3) 


\section{Cureus}

Absent

82(54.7)

Extranodal extension

Present

26(17.3)

Absent

124(82.7)

Histological subtypes

Non-keratinizing

Keratinizing

$90(60)$

Non-keratinizing with maturation

46(30.7)

Histological grade

Grade-I

42(28)

Grade-II

94(62.7)

Grade-III

14(9.3)

Perineural invasion

Present

18(12)

Absent

132(88)

Recurrence

Yes

99(66)

No

51(34)

\section{TABLE 1: Clinicopathologic features of population under study}

SD, standard deviation

Among 99 cases in which recurrence was observed, 61 cases (61.6\%) had recurrence at the primary tumor site and 38 cases (38.3\%) had recurrence in the neck.

The most common risk factor was pan/ gutka usage (62.0\%) followed by smoking (10.7\%). Adjuvant chemotherapy and radiation therapy were given in $57.3 \%$ and $59.3 \%$ cases, respectively (Table 2 ). 


\section{Cureus}

Risk factor

Frequency $(\%)$

History of Pan/ gutka usage

Present

$93(62.0 \%)$

Absent

57 (38.0\%)

Smoking history

Present

$16(10.7 \%)$

Absent

$134(89.3 \%)$

Alcohol history

Present

Absent

$147(98.0 \%)$

Adjuvant therapy

Chemotherapy

Given

$86(57.3 \%)$

Not given

$64(42.6 \%)$

Radiation

Given

$89(59.3 \%)$

Not given

$61(40.7 \%)$

TABLE 2: Frequency of risk factors and adjuvant therapy in patients with head and neck squamous cell carcinoma included in the study $(n=150)$

\section{Association of clinicopathologic features with disease recurrence}

Table 3 shows the association of clinicopathologic features with disease recurrence. We found a significant association of disease recurrence with larger tumor size, depth of invasion and extranodal extension. Moreover, younger age ( $<30$ years) and older age ( $>50$ years) groups showed a higher rate of recurrence compared to the middle age group (30-50 years). No significant association of disease recurrence with any other clinicopathological characteristic was noted in our study.

\begin{tabular}{|c|c|c|c|}
\hline \multirow{3}{*}{ Clinicopathological characteristics } & \multicolumn{2}{|c|}{ Recurrence } & \multirow{3}{*}{ P-value } \\
\hline & \multicolumn{2}{|l|}{ n (\%) } & \\
\hline & Yes & No & \\
\hline \multicolumn{4}{|l|}{ Gender } \\
\hline Male & 72(72.7) & $41(80.4)$ & \multirow{2}{*}{$0.302^{*}$} \\
\hline Female & 27(27.3) & 10(19.6) & \\
\hline \multicolumn{4}{|l|}{ Age group } \\
\hline$\leq 30$ years & 15(15.2) & $2(3.9)$ & \multirow{3}{*}{$0.043^{\star}$} \\
\hline $31-50$ years & 39(39.4) & 29(56.9) & \\
\hline$>50$ years & 45(45.5) & 20(39.2) & \\
\hline \multicolumn{4}{|l|}{ Tumor size } \\
\hline$\leq 2 \mathrm{~cm}$ & 12(12.1) & $20(39.2)$ & \multirow[b]{2}{*}{$<0.0001^{\star}$} \\
\hline $2.1-4 \mathrm{~cm}$ & $51(51.5)$ & $23(45.1)$ & \\
\hline
\end{tabular}




\section{Cureus}

\begin{tabular}{|c|c|c|c|}
\hline$>4 \mathrm{~cm}$ & $36(36.4)$ & $8(15.7)$ & \\
\hline \multicolumn{4}{|l|}{ Depth of invasion } \\
\hline$<1 \mathrm{~cm}$ & $42(42.4)$ & $37(72.5)$ & \multirow{2}{*}{$<0.0001^{*}$} \\
\hline$\geq 1 \mathrm{~cm}$ & $57(57.6)$ & 14(27.5) & \\
\hline \multicolumn{4}{|l|}{ Site } \\
\hline Oral cavity & $69(69.7)$ & $35(68.6)$ & \multirow{4}{*}{$0.326^{\star \star}$} \\
\hline Lip & $0(0)$ & $2(3.9)$ & \\
\hline Tongue & $24(24.2)$ & 12(23.5) & \\
\hline Soft palate & $6(6.1)$ & $2(3.9)$ & \\
\hline \multicolumn{4}{|l|}{ Nodal metastasis } \\
\hline Present & $42(42.4)$ & $26(51)$ & \multirow{2}{*}{$0.319^{\star}$} \\
\hline Absent & $57(57.6)$ & $25(49)$ & \\
\hline \multicolumn{4}{|l|}{ Extra nodal extension } \\
\hline Present & $12(12.1)$ & 14(27.5) & \multirow{2}{*}{$0.019^{\star}$} \\
\hline Absent & $87(87.9)$ & $37(72.5)$ & \\
\hline \multicolumn{4}{|l|}{ Histological subtypes } \\
\hline Non-keratinizing & $12(12.1)$ & $2(3.9)$ & \multirow{3}{*}{$0.107^{\star \star}$} \\
\hline Keratinizing & $54(54.5)$ & $36(70.6)$ & \\
\hline Non-keratinizing with maturation & $33(33.3)$ & $13(25.5)$ & \\
\hline \multicolumn{4}{|l|}{ Histological grade } \\
\hline Grade-I & $30(30.3)$ & $12(23.5)$ & \multirow{3}{*}{$0.131^{\star \star}$} \\
\hline Grade-II & $57(57.6)$ & $37(72.5)$ & \\
\hline Grade-III & $12(12.1)$ & $2(3.9)$ & \\
\hline \multicolumn{4}{|l|}{ Perineural invasion } \\
\hline Present & $12(12.1)$ & $6(11.8)$ & \multirow{2}{*}{$0.949^{*}$} \\
\hline Absent & 87(87.9) & 45(88.2) & \\
\hline
\end{tabular}

\section{TABLE 3: Association of clinicopathological features with disease recurrence}

${ }^{\star}$ Chi-square test was applied, ${ }^{\star *}$ Fisher exact test was applied.

Similarly, univariate and multivariate analyses revealed that tumors with $\geqslant 1 \mathrm{~cm}$ depth of invasion and the presence of extranodal extension were more likely to have disease recurrence than tumors with $<1 \mathrm{~cm}$ depth of invasion and without extranodal extension (Table 4).

\begin{tabular}{|c|c|c|c|c|}
\hline Clinicopathological characteristics & P-value & Odds ratio (95\% Cl) & P-value & Adjusted Odds ratio $(95 \% \mathrm{Cl})$ \\
\hline \multicolumn{5}{|l|}{ Gender } \\
\hline Male & 0.304 & $0.650(0.286-1.478)$ & & \\
\hline Female $^{\star}$ & & 1 & & \\
\hline \multicolumn{5}{|l|}{ Age groups } \\
\hline$\leq 30$ years & 0.132 & $3.333(0.696-15.968)$ & & \\
\hline $31-50$ years & 0.157 & $0.598(0.293-1.219)$ & & \\
\hline
\end{tabular}




\section{Cureus}

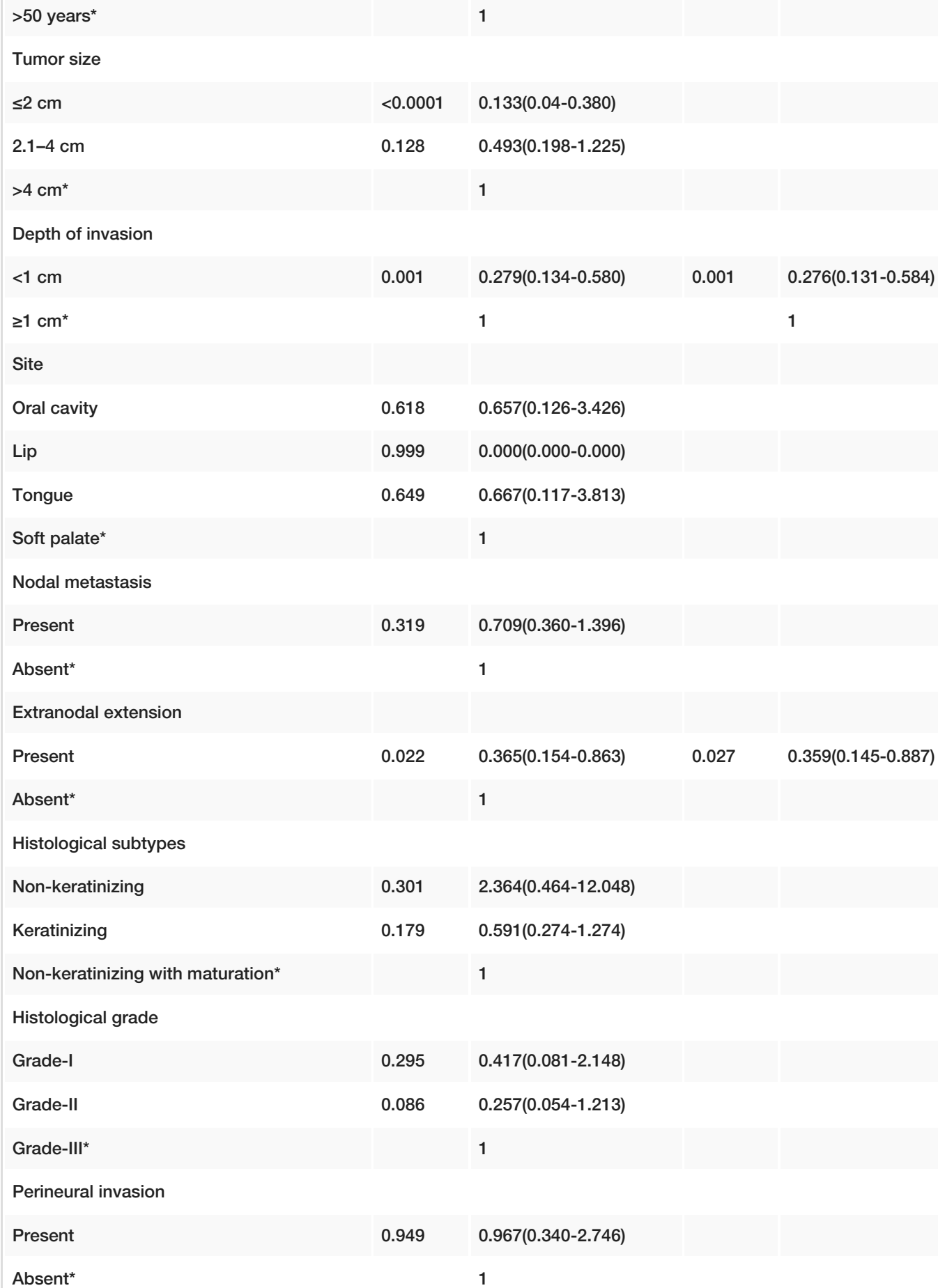

Perineural invasion

Present

Absent $^{*}$

1

\section{TABLE 4: Univariate and multivariate analysis for disease recurrence with clinicopathological} features of population under study

Univariate and multivariate binary logistic regression were applied. *Reference group. $\mathrm{Cl}$, confidence interval.

Survival analysis using the Kaplan-Meier method for HNSCC revealed a significant difference in disease free survival in patients with more than $2 \mathrm{~cm}$ tumor size and $\geqslant 1 \mathrm{~cm}$ depth of invasion than cases with $\leqslant 2 \mathrm{~cm}$ tumor size and $<1 \mathrm{~cm}$ depth of invasion (Figures 2, 3,4). 


\section{Cureus}

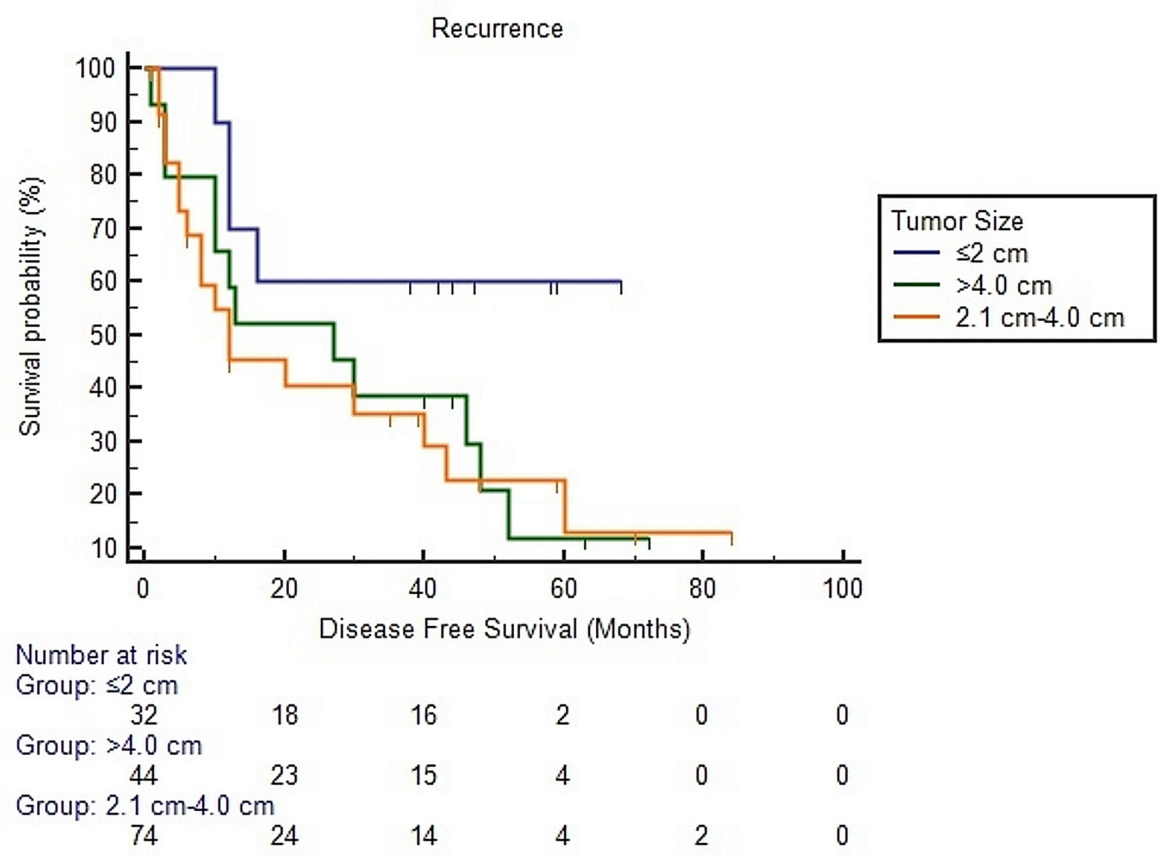

FIGURE 2: Survival analysis using the Kaplan-Meier method for head and neck squamous cell carcinoma with respect to tumor size

Log rank $p$-value $=0.002$

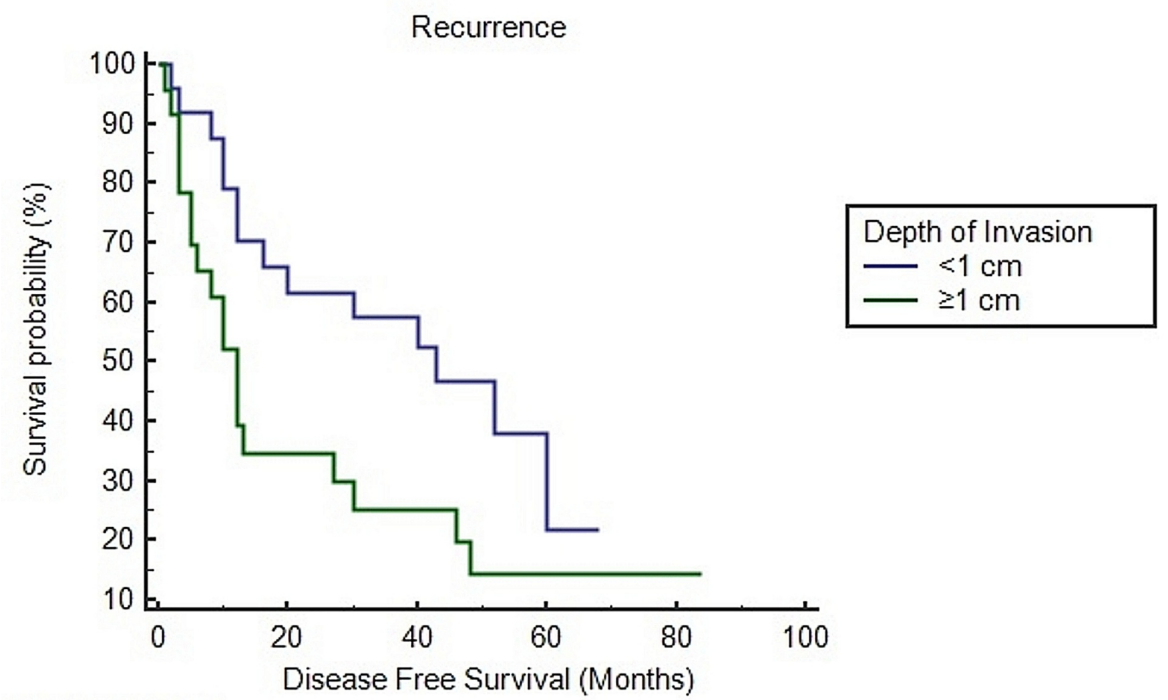

Number at risk

Group: $<1 \mathrm{~cm}$

$\begin{array}{cccccc}79 & 43 & 31 & 4 & 0 & 0 \\ \text { Group: } \geq 1 \mathrm{~cm} & & & & & \\ 71 & 22 & 14 & 6 & 2 & 0\end{array}$

FIGURE 3: Survival analysis using the Kaplan-Meier method for head and neck squamous cell carcinoma with respect to depth of invasion

Log rank $p$-value $=<0.0001$ 


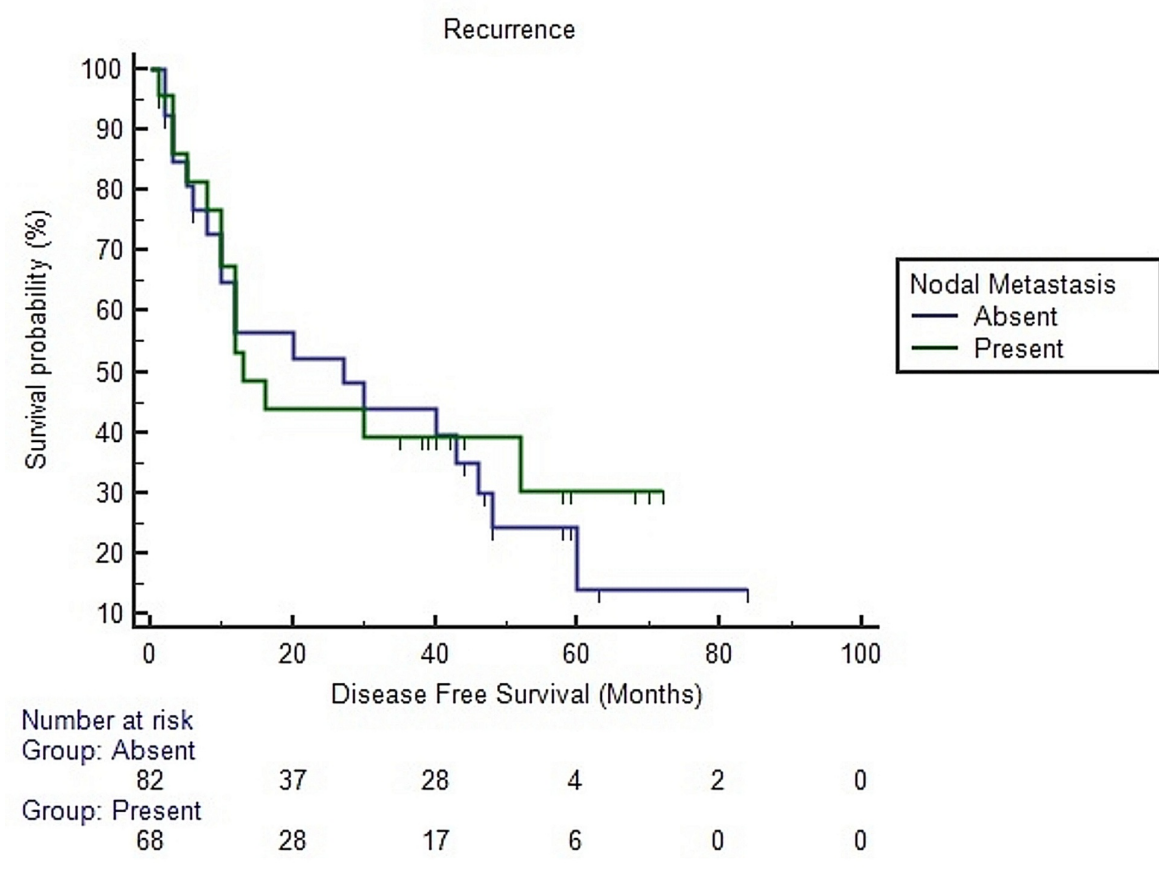

FIGURE 4: Survival analysis using the Kaplan-Meier method for head and neck squamous cell carcinoma with respect to nodal metastasis

Log rank p-value $=0.526$

\section{Discussion}

In this study, we found a high rate of recurrence in our cases of HNSCC despite tumor-free resection margins on the frozen section. Moreover, we noted that the presence of recurrence was significantly associated with tumor size, depth of invasion and extranodal extension.

Various studies have evaluated the recurrence of HNSCC in locoregional population. A study conducted in China assessed disease recurrence in 275 patients with oral squamous cell carcinoma. They reported $32.7 \%$ recurrence rate in their study; however, in their study, $66.2 \%$ cases were early-stage cancers (T1+T2). Recurrence in late-stage cancers (T3+T4) in their study was $57 \%$. They also found that tumor (T) stage, nodal (N) stage and degree of differentiation were the major factors determining disease recurrence [8]. We also found a significant association of tumor size and depth of invasion with disease recurrence; however, no significant association of disease recurrence was noted with the degree of differentiation in our study. Another study, conducted in Brazil, compared cases of HNSCC with and without recurrence. They found that the site (tongue) and degree of differentiation were the factors associated with disease recurrence [9]. However, we did not find any significant association of tumor site with disease recurrence in our study. An important factor that was not assessed carefully in these studies was extranodal extension as a recurrence of HNSCC typically occurs either at the primary site or in the neck and presence of extranodal extension is an important factor that can lead to disease recurrence in the neck. Although margins of primary tumor are carefully assessed and closed margins are re-shaved to get a margin-free resection, neck specimen is typically not assessed for margins and therefore, in the presence of extranodal extension, the chances of recurrence in the neck increase.

An important prognostic factor in oral cancers is margin-free resection, and the frozen section has pivotal importance in this regard. There are two ways for intra-operative pathological consultation. The first and more prevalent is tumor-bed margin evaluation and second is sending a whole resected specimen for frozen section assessment (tumor-specific margin). In tumor-bed evaluation for the frozen section, the surgeon after removal of tumor sends shaving from resected tumor bed. Any tumor present in the shaving specimen is considered positive and re-shaving is done. The disadvantage of this technique is that the differentiation between a positive margin and close margin (i.e. $<5 \mathrm{~mm}$ ) is not possible. Second, in case of large tumors, tumor bed is huge and evaluation of whole tumor bed is impossible. The second method, i.e. evaluation of whole specimen by frozen section, although cumbersome and time-consuming has recently been proved to be more effective in reducing the chances of recurrence and improving disease-free survival in patients with oral squamous cell carcinoma [10-12]. We at LNH routinely practice this technique, in which all the margins of the resection specimen are evaluated on frozen section and rapidly communicated to the surgeon. Despite margin-free resections, we found a high rate of recurrence in our study. This signifies the importance of 
other factors that affect disease recurrence, that is, tumor size and depth of invasion. Moreover, the poor prognostic importance of extranodal extension should not be underscored in these circumstances.

One of the major limitations of our study was limited sample size. Second, molecular analysis for HPV status was not determined, as HPV-induced HNSCC behave in a less aggressive fashion than non-HPV induced cancers. Although we found significant associations in our study, there were multiple confounding factors that could not be controlled in such study design, for instance, different combinations of chemotherapy and radiation therapies were given to different patients based on oncologist decision and multidisciplinary team meetings that could also alter individual outcomes.

\section{Conclusions}

A high rate of disease recurrence was noted in HNSCC in our study after tumor-free resection margins on the frozen section. A substantial proportion of recurrence occurred in the neck in our study. Apart from tumor size and depth of invasion, which are known risk factors of disease recurrence in HNSCC, we also noted a significant association of disease recurrence with extranodal extension. Therefore, we suggest that, in the presence of extranodal extension, resection margins of neck dissection specimen should also be assessed along with primary specimen resection margins.

\section{Additional Information \\ Disclosures}

Human subjects: Consent was obtained by all participants in this study. Ethical Review Committee of Liaquat National Hospital issued approval 0555-2020 LNH-ERC. Ethical Review Committee of Liaquat National Hospital approved the study. Animal subjects: All authors have confirmed that this study did not involve animal subjects or tissue. Conflicts of interest: In compliance with the ICMJE uniform disclosure form, all authors declare the following: Payment/services info: All authors have declared that no financial support was received from any organization for the submitted work. Financial relationships: All authors have declared that they have no financial relationships at present or within the previous three years with any organizations that might have an interest in the submitted work. Other relationships: All authors have declared that there are no other relationships or activities that could appear to have influenced the submitted work.

\section{References}

1. Hashmi AA, Hussain ZF, Hashmi SK, et al.: Immunohistochemical over expression of $\mathrm{p} 53$ in head and neck Squamous cell carcinoma: clinical and prognostic significance. BMC Res Notes. 2018, 11:433. 10.1186/s13104-018-3547-7

2. Hashmi AA, Hussain ZF, Aijaz S, et al.: Immunohistochemical expression of epidermal growth factor receptor (EGFR) in South Asian head and neck squamous cell carcinoma: association with various risk factors and clinico-pathologic and prognostic parameters. World J Surg Oncol. 2018, 16:118. 10.1186/s12957-018-1425-3

3. Naz S, Salah K, Khurshid A, Hashmi AA, Faridi N: Head and neck squamous cell carcinoma - comparative evaluation of pathological parameters in young and old patients. Asian Pac J Cancer Prev. 2015, 16:40614063. 10.7314/apjcp.2015.16.9.4061

4. Hashmi AA, Aijaz S, Irfan M, Hussain ZF, Hashmi SK, Asif H, Faridi N: Low p27kip1 expression in head and neck squamous cell carcinoma: association with risk factors and adverse outcomes. Appl Cancer Res. 2019, 39:5. 10.1186/s41241-019-0074-3

5. Akram S, Shabbir A, Mirza T: Association of high risk human papilloma virus (HPV-16/18) with P16 protein in oral premalignant lesions and oral squamous cell carcinoma. Pak J Med Dent. 2019, 9:4-11. 10.36283/PJMD8-4/002

6. Hashmi AA, Younus N, Naz S, et al.: p16 immunohistochemical expression in head and neck squamous cell carcinoma: association with prognostic parameters. Cureus. 2020, 13:e8601. 10.7759/cureus.8601

7. Kazmi FN, Adil A, Ghaffar S, Ahmed F: Association between tumour volume and recurrence of squamous cell carcinoma of the head and neck. J Pak Med Assoc. 2012, 62:1129-1133.

8. Wang B, Zhang S, Yue K, Wang XD: The recurrence and survival of oral squamous cell carcinoma: a report of 275 cases. Chin J Cancer. 2013, 32:614-618. 10.5732/cjc.012.10219

9. Camisasca DR, Silami MA, Honorato J, Dias FL, de Faria PA, Lourenço Sde Q: Oral squamous cell carcinoma: clinicopathological features in patients with and without recurrence. ORL J Otorhinolaryngol Relat Spec. 2011, 73:170-176. 10.1159/000328340

10. Chiosea SI: Intraoperative margin assessment in early oral squamous cell carcinoma . Surg Pathol Clin. 2017, 10:1-14. 10.1016/j.path.2016.10.002

11. Thomas Robbins K, Triantafyllou A, Suárez C, et al.: Surgical margins in head and neck cancer: intra- and postoperative considerations. Auris Nasus Larynx. 2019, 46:10-17. 10.1016/j.anl.2018.08.011

12. Buchakjian MR, Tasche KK, Robinson RA, Pagedar NA, Sperry SM: Association of main specimen and tumor bed margin status with local recurrence and survival in oral cancer surgery. JAMA Otolaryngol Head Neck Surg. 2016, 142:1191-1198. 10.1001/jamaoto.2016.2329 